\title{
Conditions for Investment in Genetic Biocontrol of Pest Vertebrates in Australia
}

\author{
Lucy Carter ${ }^{1,2 *}$, Aditi Mankad ${ }^{1,2}$, Susan Campbell ${ }^{3}$, Wendy Ruscoe ${ }^{2,4}$, Kevin P. Oh $^{4,5}$, \\ Peter R. Brown ${ }^{2,4}$, Margaret Byrne ${ }^{6}$, Mark Tizard ${ }^{2,4,7}$ and Tanja Strive ${ }^{2,4}$ \\ ${ }^{1}$ Commonwealth Scientific and Industrial Research Organisation - Land and Water, Brisbane, QLD, Australia, ${ }^{2}$ Centre for \\ Invasive Species Solutions, Canberra, ACT, Australia, ${ }^{3}$ Department of Primary Industries and Regional Development, Albany, \\ WA, Australia, ${ }^{4}$ Commonwealth Scientific and Industrial Research Organisation - Health and Biosecurity, Canberra, ACT, \\ Australia, ${ }^{5}$ Applied BioSciences, Macquarie University, North Ryde, NSW, Australia, ${ }^{6}$ Department of Biodiversity, \\ Conservation and Attractions, Kensington, WA, Australia, ${ }^{7}$ Commonwealth Scientific and Industrial Research Organisation - \\ Health and Biosecurity, Geelong, VIC, Australia
}

Managing pest vertebrate species in Australia is a significant challenge for government, industry, research sectors and land-managers. Innovative tools such as genetic biocontrol offers decision-makers a potentially effective means of reducing the impact of pest species incursions. To determine the conditions for investment in genetic biocontrol, we applied qualitative engagement methodologies to identify and integrate existing knowledge of pest species research and management in Australia. Two facilitated workshops were held to determine key topics related to genetic biocontrol technologies for selected pest species. The topics explored during workshop discussions included: identifying existing knowledge gaps; risk perceptions; social and ethical considerations and; industry and business considerations. The workshops' aim was to assess the potential, the priorities and the risk parameters among expert stakeholders and decision-makers for using genetic biocontrol approaches to reduce the impacts of key pest species in Australia. This paper reports on the design, process and outcomes of each workshop to inform the creation of a decision framework. Stakeholders were cautiously optimistic of pursuing continued research and development for vertebrate pest management in Australia. However, employing an appropriate, transparent process for incorporating diverse stakeholder perspectives on genetic biocontrol technologies is essential to ensure their development and use remains supported. This outcome will require meaningful investment in both social science investigations and well-considered engagement processes concurrent with biotechnology development globally.

Keywords: genetic biocontrol, gene drive, vertebrate pests, stakeholder engagement, social acceptability, decision framework

Received: 01 November 2021 Accepted: 20 December 2021 Published: 31 January 2022

Citation

Carter L, Mankad A, Campbell S,

Ruscoe W, Oh KP, Brown PR,

Byrne M, Tizard M and Strive T (2022)

Conditions for Investment in Genetic

Biocontrol of Pest Vertebrates in

Australia. Front. Agron. 3:806569.

doi: 10.3389/fagro.2021.806569

\section{INTRODUCTION}

Established vertebrate pests are a significant social, economic and environmental burden for Australia (Pimentel, 2002; Bradshaw et al., 2021). Invasive species incursions can affect agricultural productivity, access to export markets, public health, and the conservation of biodiversity, natural and built environments (Hart and Bomford, 2006). Incursions cost Australia's primary producers in excess of AUD\$700 million per annum and are the primary force driving the decimation of Australia's unique fauna and flora (Kearney et al., 2019). These cumulative effects can lead to 
increased production costs, loss or restrictions to export trade, reduced tourism, loss of biodiversity, greater public health costs and reduced public amenity (McLeod, 2016).

Depending on the species, location and extent of an incursion, a combination of techniques is typically required to achieve sustained control of vertebrate pests at levels acceptable to management. There are five main classes of techniques for pest animal control currently available in Australia, including removal (poisoning, shooting, trapping, mustering), habitat alteration (warren ripping, removal of harbor), alteration of land management practices, exclusion fencing and fertility and biological control (Braysher, 2017). Funding for control efforts primarily comes from private landholders (e.g., farmers), state and federal governments, and non-government organizations (NGOs). Much of this effort is considered reactive to existing pest problems and does not necessarily prevent or manage new incursions (Doherty et al., 2016; Epanchill-Niell, 2017). Developing control tools and methods that deliver improved welfare outcomes for both target and non-target animals is also an important consideration in pest management (Littin et al., 2014; Mankad et al., 2019; Hampton et al., 2020).

Refinement of existing practices and development of new control strategies are required to add depth to the management toolbox. Rapid advancements are now being made to develop technologies to control invasive species and their impacts genetically (Teem et al., 2020). Compared to conventional management methods, genetic biocontrol technologies (GBTs herein) potentially offer numerous advantages including improved target specificity, increased efficiency, and better animal welfare outcomes (Campbell et al., 2015; TARC X, 2016).

However, investment in GBTs raises multiple and interconnected social, ecological and political considerations (Brown et al., 2018; Rudenko et al., 2018). Investment decisions need to be made in consideration of localized problem articulation, environmental and ecological implications of control, and associated innovation risks (Hartley et al., 2016). Real and predicted economic impacts, sociocultural connections and implications for a particular species and its control, as well as more formal regulatory requirements, are also equally important factors to consider (Clark et al., 2020). Finally, investment in GBTs must also consider the counterfactual, such as triple-bottom line impacts associated with inaction, and the risks that longer-term inaction presents.

While proof of concept for GBTs such as gene drive for vertebrates is being realized, early engagement with a diverse range of stakeholders is considered key to a responsible research agenda [Hartley et al., 2016; National Academy of Sciences Engineering Medicine (NASEM), 2016]. To understand multiple perspectives of GBTs and provide a basis for consideration of a framework to progress development of these technologies, the authors undertook targeted consultation with key Australian stakeholders. The work builds on previous research that identified key knowledge gaps in using gene drives for invasive species control (Moro et al., 2018) as well as the need for innovative approaches and the challenges this technology brings (Legros et al., 2021). The investment decision framework presented here extends this scholarship to consider the multiple political, social and institutional considerations key to decisionmaking about using GBTs for pest species management.

Recent research has highlighted divergent views among experts involved in gene drive research, especially in relation to engagement, decision-making and ethical acceptability (de Graeff et al., 2021a,b). Generating multistakeholder buy-in has previously been considered a critical component of successful stakeholder engagement, as well as knowledge translation and improved research impact (Shackleton et al., 2019; Carter, 2020). These considerations drove both the design and the conduct of each workshop and informed the development of an investment decision framework which articulates the broader institutional environment for GBT investment in Australia.

The aim of this paper is to reflect on a process of multistakeholder engagement for the development and identification of conditions for investment in GBTs for vertebrate pests. We report on the outcomes of two research workshops which brought together mostly Australian ${ }^{1}$ industry, civil society, government and research stakeholders to discuss the conditions under which decisions about investment in GBTs could be made. The workshops were held to trigger dialogue among key stakeholders with the intention of building understanding and providing opportunities for future collaboration and consensus-building. We anticipate these insights will assist with multistakeholder discussions in other countries with similar challenges, providing the relevant principles to pursue similar forums for collaboration.

We begin the paper with a brief introduction to the technological, regulatory and social factors relevant to considering genetic biocontrol as an investment option before presenting the Investment Decision Framework. A detailed explanation of methods follows along with a discussion of results and implications for future science planning and policy development.

\section{GENETIC BIOCONTROL AS AN INVESTMENT OPTION}

\section{Technological and Environmental Factors}

GBTs use genome editing methods such as CRISPR/Cas9 to disrupt normal reproduction or development in a heritable way to achieve population control of pest species (McFarlane et al., 2018; Teem et al., 2020). The development and application of GBTs is complex, may not be appropriate for all species, and may take many years to reach a level of readiness suitable for deployment. For each pest species, there are multiple knowledge gaps that will need to be addressed before genetic biocontrol options are able to be realized (Moro et al., 2018).

Unlike most toxin-based methods which may often impact non-target species, including humans, most proposed GBTs rely on sexual reproduction for transmission, thereby maximizing target specificity. Additionally, many GBT applications such as synthetic homing gene drives are self-propagating, which minimizes resources and effort required for sustained deployment and management compared to conventional

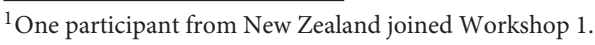


controls or existing genetic biocontrols like sterile insect technique (Knipple, 2013). Such efficiencies are particularly important for use over large geographic areas or remote sites where repeated management actions can be difficult or cost prohibitive. Moreover, some proposed technologies include selfterminating mechanisms which degrade over a predetermined time interval, thereby limiting spread to non-target populations and preventing the accumulation of modified genetic material in the environment or bioaccumulation within food webs (Prowse et al., 2017). Finally, GBT methods which achieve population suppression via skewing of sex ratios or embryo viability are arguably more humane than poisons or pathogen-based biocontrols (Leitschuh et al., 2018).

Despite the prospective benefits, the application of GBTs to control invasive species may carry both environmental and technical risks that will need to be identified and managed on a case-by-case basis (Oye et al., 2014; Hayes et al., 2018). Where successful application of a GBT leads to large-scale control of an invasive species, careful consideration needs to be given to undesirable ecological outcomes (reviewed in Kopf et al., 2017). These may include, but are not limited to, increased predation pressure on already vulnerable native species from other invasive species (meso-predator release, e.g., Molsher et al., 2017); adverse changes to abiotic factors (e.g., water quality) and other negative food-web outcomes (e.g., loss of prey for a native predator) (Courchamp et al., 2003). From a technical perspective, the very self-propagating characteristic that provides such efficiencies to some GBTs (e.g., homing gene drive) presents a risk of unmitigated spread beyond the target pest population should the genome-edited animals interbreed with individuals in nontarget populations (Webber et al., 2015). There is also a risk of populations spontaneously evolving resistance to GBT elements, thus rendering the control mechanism ineffective (Unckless et al., 2017). Additionally, most proposals require the release of significant numbers of genetically-modified pest animals to effectively spread the GBT elements, thereby creating a local risk of additional direct damage due to increased pest numbers (David et al., 2013).

\section{Regulatory and Governance Factors}

With regulators anticipating successful development and release of GBT within 5-20 years, discussions on the extent to which existing national and international regulations will be fit-for-purpose are occurring despite the absence of any 'field-ready' GBTs (e.g., Emerson et al., 2017; Kuzma et al., 2018; Rudenko et al., 2018; Royal Society Te Apãrangi, 2019; European Commission, https://ec.europa.eu/food/plants/geneticallymodified-organisms/gmo-legislation_en). In Australia, under the Gene Technology Act (2000), the National Gene Technology Scheme (NGTS) sets out the understanding between Commonwealth, state and territory governments regarding the establishment of a nationally consistent regulatory system for gene technology. The Gene Technology Act (2000) requires consideration of risks to the health and safety of humans and the environment, however there are no specific provisions under this act for consideration of threats and benefits to the economy (e.g., primary industries) from the application of GBTs. In parallel to the NGTS, the Intergovernmental Agreement on Biosecurity (IGAB), is a key agreement signed by all Australian jurisdictions outlining national biosecurity goals and objectives and clarifying roles, responsibilities and governance arrangements. Australia's National Biosecurity Committee (NBC) was formally established under the IGAB and is responsible for managing a national, strategic approach to plant and animal biosecurity threats to agricultural, environmental and societal assets. Currently there is no expertise on the committee to direct research and development into GBTs for vertebrate pests in Australia.

Beyond the formal regulatory structures and assessments GBTs must satisfy, there is a myriad of broader governance considerations relevant to their development and use. These include consideration of their social, ethical and cultural implications (Kuzma and Rawls, 2016; Emerson et al., 2017), whether GBTs contribute to a shared public good (Santos, 2020), and whether the science generated by research communities generate institutional reflexivity and change (Macnaughten and Chilvers, 2014). That is, whether learnings from stakeholder engagement are adopted by organizations investing in the research. As such, governance frameworks for GBTs, i.e., processes for establishing clear, transparent communication, inclusiveness and equity among all stakeholders and publics, require further attention and development by involved jurisdictions.

\section{Social and Institutional Factors}

In the past 5 years, there has been a significant increase in the exploration of the social and institutional factors influencing research and development of GBTs. Public attitudes toward novel genetic tools using synthetic biology (c.f., Mankad et al., 2019; Synthetic Biology Future Science Platform, 2020) and the broader normative questions raised by public participation in science in the context of gene drives (c.f. Thizy et al., 2019; Ledingham and Hartley, 2021) are examples of these efforts.

Much of the empirical work in Australia and New Zealand has focused on public acceptability, perceived risks of genetic interventions and affect-driven decision-making (cf. MacDonald et al., 2020; Mankad et al., 2020; Carter et al., 2021). In the Australian invasive species context, the Australian public is moderately to strongly aware of the negative impact pest species have on our landscapes, and conditionally willing to consider novel technologies to manage the problem (Mankad et al., 2019). This research also shows that while a stated intention to support the development of novel approaches for pest control is moderately strong, it does vary depending on existing social and cultural values linkages between communities and the species in question (Mankad et al., 2019). This is likely to be even more important if the pest species is native. Thus, any genetic biocontrol designed to manage pests must consider the full context within which that pest currently exists.

Public opinion of novel genetic biocontrol is often cited as a key driving factor in high-level decision making for investment in genetic biocontrol (Brossard et al., 2019). However, to date, there has been relatively less engagement with local land managers whose perspectives could provide a useful complement to the engagement narrative around genetic 
biocontrol, and who could highlight more business-oriented criteria for decision-making and support in relation to genetic biocontrol technologies (Kofler et al., 2018; Kuzma et al., 2018). To date, policy and industry stakeholder perspectives are largely missing from genetic biocontrol conversations in Australia. Presently, it is not clear how investment decisions are made amongst these key stakeholders or what priorities they may value when evaluating an investment business case for genetic biocontrol.

\section{The Investment Decision Framework}

A cross-jurisdictional, multidisciplinary team led by CSIRO designed two workshops in 2020, each event aiming to bring together expert knowledge across research, policy, and industry sectors. The workshops were designed to inform two key research questions: What are the current priorities in managing the impact of pest species for key Australian research, industry and government stakeholders? What factors influence investment in genetic biocontrol options for Australian stakeholder organizations?

The research took a cross-disciplinary approach to framing the issue of genetic biocontrol. In addition to discussion of the technical feasibility of GBTs, the workshops were designed to capture the social and institutional aspects of decision-making for investment in GBTs. We applied qualitative methods in the form of face-to-face group discussions, online interactions and a short survey to reveal the conditions for investment in GBT among key Australian stakeholders. Our findings identify the criteria that are valued by a cross-section of diverse Australian organizational stakeholders when considering the case for investment in GBTs.

The framework presented in Figure 1 below emerged from analysis of workshop discussions. The framework informs investor decision-making by articulating the range of drivers (i.e., conditions) for investment in GBTs for Australian government, industry and research stakeholders. While "investment" typically refers to the provision of funding, the project applied a broader definition of investment in GBTs to include: partnering, networking and advocacy; strengthening governance pathways and; the brokering of knowledge and partnerships. A broader interpretation of investment is important when considering the diversity of capacities, resources and interests a diverse range of organizations can contribute to invasive species research and management (Shackleton et al., 2019).

The Investment Decision Framework (Figure 1) represents collated findings from both workshops and highlights antecedent factors influencing the current investment and management environment (e.g., diverse investment drivers and competing priorities); the conditions for investment in genetic biocontrol technologies (e.g., established safety and efficacy); and the enabling conditions for investment in genetic biocontrol (e.g., alignment with funding, program and political priorities). Interestingly, the four conditions identified by workshop participants as essential for investment in genetic biocontrol are also those identified as key to effective and responsible science development globally [National Academy of Sciences Engineering Medicine (NASEM), 2016; Teem et al., 2020].
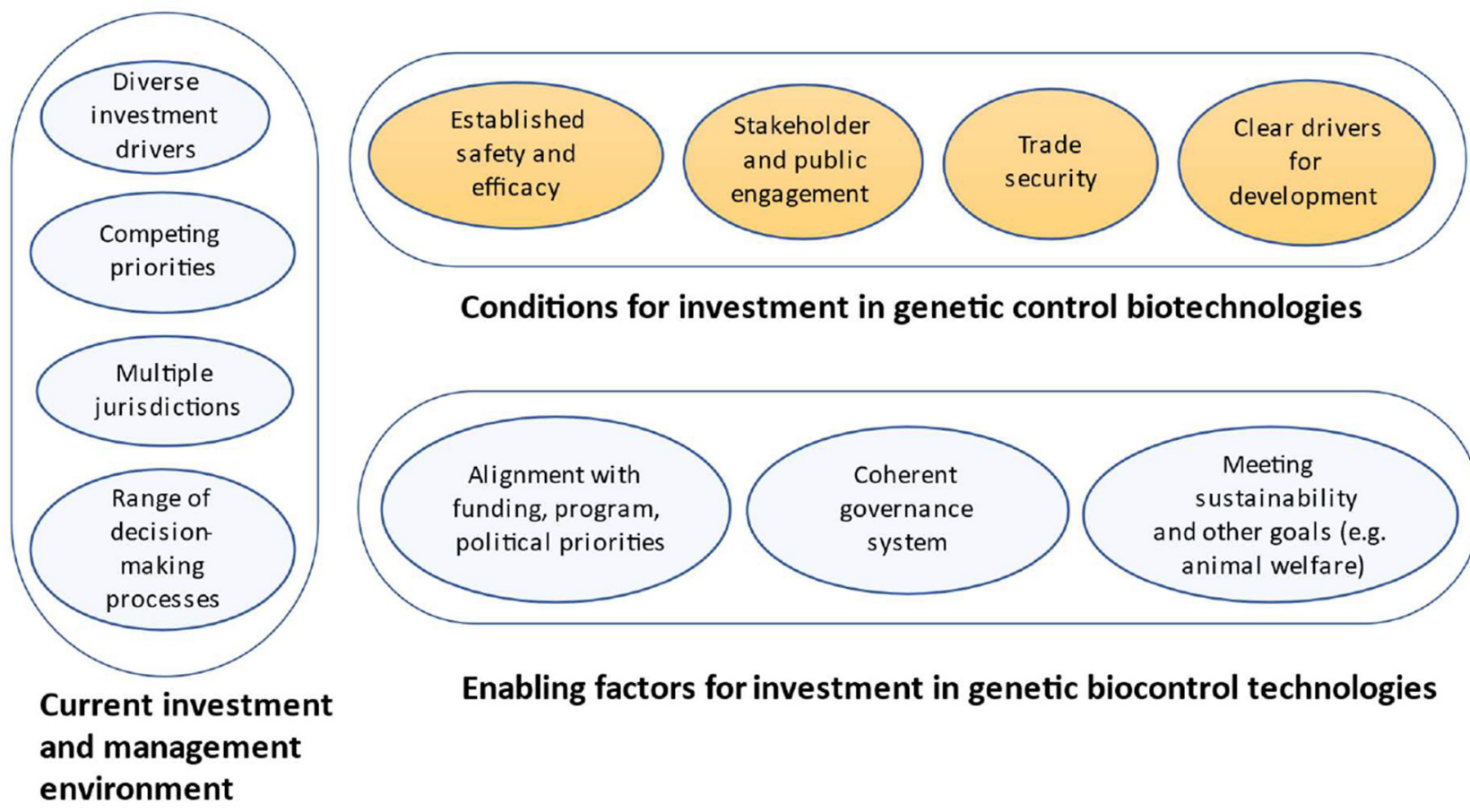

Conditions for investment in genetic control biotechnologies

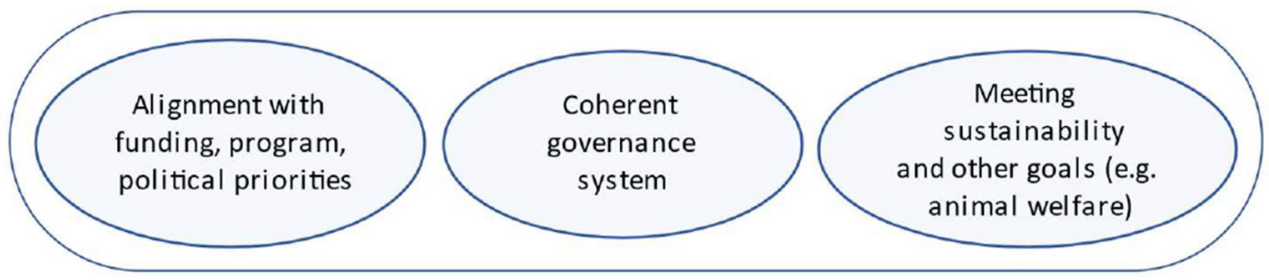

Enabling factors for investment in genetic biocontrol technologies

FIGURE 1 | Investment decision framework for genetic biocontrol of vertebrate pests in Australia, with conditions for investment highlighted in orange. 
The conditions for investment cluster incorporates four key themes revealed by workshop participants as essential for investment in GBTs and include clear drivers for technology development, and public and stakeholder engagement. The investment and management environment cluster denotes the multiple, interrelated and at times complex factors that influence institutional decision-making in relation to GBTs. Enabling factors convey the considerations identified by participants as favorable to investment in GBTs.

\section{WORKSHOP DESIGN}

The Investment Decision Framework was created from the outputs of two Australian stakeholder workshops-the key details of which are summarized in Table 1 below. Workshop 1 (W1 herein) was held face-to-face in Canberra, Australia while workshop 2 (W2 herein) was convened online due to evolving circumstances in relation to the COVID-19 pandemic. Each workshop invited participants from a cross-section of representative stakeholder organizations including industry, research, civil society and government. Each workshop had distinct but interrelated objectives and was designed to determine the knowledge sets identified as a requirement to technology deployment (W1) and the institutional context and drivers key

TABLE 1 | Synopsis of workshop participants, methods and objectives.

Workshop 1: Pest priorities and their technical, business, ecological and social risks

Objective: Identify priorities and impacts in managing pest species for key Australian research, industry and government stakeholders

\begin{tabular}{|c|c|}
\hline Invited participants & Methods (Face-to-face) \\
\hline $\begin{array}{l}\text { Science and industry professionals from } \\
\text { a range of backgrounds including } \\
\text { government, civil society and industry } \\
\text { identified as having a direct interest in } \\
\text { the genetic biocontrol of vertebrate } \\
\text { pests. } \\
54 \text { participants invited; } 34 \text { attended }\end{array}$ & $\begin{array}{l}\text { Construction of stakeholder matrix } \\
\text { Pre-workshop pilot survey } \\
\text { Scene-setting presentations } \\
\text { Face-to-face group exercises } \\
\text { and discussions }\end{array}$ \\
\hline
\end{tabular}

Workshop 2: Institutional decision-making and investment in genetic biocontrol

Objective: Understand the institutional drivers, conditions and enablers of investment in genetic biocontrol for key Australian stakeholders

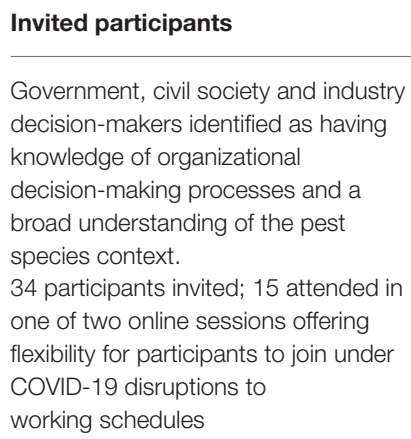

Government, civil society and industry decision-makers identified as having knowledge of organizational decision-making processes and a broad understanding of the pest species context.

34 participants invited; 15 attended in

one of two online sessions offering

flexibility for participants to join under

COVID-19 disruptions to

working schedules

to the successful adoption of genetic biocontrol interventions in Australia (W2). Both workshops were designed by the authorship team in consultation with an independent facilitator (PiqueGlobal) who also led the proceedings for each workshop. The outcomes of both workshops informed the creation of the Decision Framework (Figure 1).

The employment of an independent facilitator allowed the team to focus on facilitating small group work and capturing the key themes of discussions. Independent facilitation for plenary sessions also ensured that the project team leading the consultation maintained some distance from proceedings and reduced the potential for influencing the direction of discussions and subsequent outcomes. Table 1 describes the objectives of each workshop, along with the methods used to collect data to construct the Investment Decision Framework.

W1 attendees participated in a full day workshop to identify current pest priorities and their impacts along with the risks of using GBTs to manage incursions. A range of group exercises (detailed below) were used to elicit expert knowledge. W2 consisted of one 2.5-h online meeting, offered across two alternative timeslots (morning or afternoon). The focus of discussion for W2 was designed to uncover the institutional decision-making ecosystem including the range of factors and drivers that influence how, why and when decisions are made about invasive species research and development. In addition, the W2 set out to identify the enablers and disablers for organizations to invest in genetic biocontrol options.

\section{METHODS}

\section{Development of a Stakeholder Matrix}

The project applied a phased, adaptive approach to stakeholder engagement beginning with the construction of a structured stakeholder matrix. The matrix was developed by the project team, who themselves represented multiple disciplinary backgrounds including ecology, genetics and social science. The matrix was created prior to W1 and was subsequently adapted to meet the objectives of W2.

The research objective for $\mathrm{W} 1$ was to identify a comprehensive spectrum of drivers, risks and impacts of pest incursions. The team was guided by the approaches of Urquhart et al. (2017) and others (Thresher and Kuris, 2004; Kirk et al., 2020) who previously elicited expert opinion in a range of complex and contested biosecurity contexts. In creating a targeted stakeholder matrix, the team was especially careful to distinguish among the roles and expertise of a broad range of stakeholders, including identifying existing links between stakeholders and their institutional capacity to influence biosecurity outcomes more broadly (c.f. Urquhart et al., 2017). Moon and Blackman (2015) and others, have found scientists and policy makers hold different views on the role of scientific evidence where scientists often consider evidence to be the primary driver of policy-making while policymakers have a broader view of the role of science as one component of a larger pool of considerations and most relevant to monitoring outcomes.

The matrix intended to systematically capture multiple institutional scales and knowledge types considered essential in 
biosecurity governance (Reed and Curzon, 2015). It included representation at organizational and individual levels; coverage across jurisdictional and geographic scales; coverage across a range of knowledge sectors including government, research and civil society; inclusion of representatives with diverse interests and; gender and age diversity.

Among the criteria applied, equal representation of various knowledge domains was considered essential for the development of a balanced list. Care was taken not to "stack" expert knowledge from a single domain. The research team had a genuine intention to include Indigenous contribution to both workshops; however, we were unable to build the necessary relationships required in the timeframe available to complete the project. A concrete plan for inclusion of Indigenous knowledge in future science planning is required for future engagement initiatives.

Adapted to fit the scope of each workshop, the matrix evolved over time and remained dynamic to availability of attendees. At the time of matrix development and workshop design, rapidly changing local circumstances, including bushfire emergencies and the COVID-19 pandemic, required agility in planning. After initially generating a long list of potential invitees, a short list of potential participants was selected and endorsed by the project's steering committee.

For W2, a revised matrix was generated to reflect our purpose to understand the broader institutional decision-making environment and the conditions under which government, industry and civil society might invest in genetic biocontrol. In this instance, multisectoral decision-makers were the target of consultation.

\section{Pre-workshop Survey}

Prior to W1, the team piloted a short open-ended survey to: (1) elicit expert opinion using well-defined constructs (2) inform the workshop design and; (3) "prime" participants to the topics for discussion in W1. The results of the survey were fed back to participants prior to the workshop and communicated in a W1 plenary session.

Stakeholders invited to take part in the pilot survey were a systematic random subsample of the total stakeholder pool $(n=20)$. Individuals were selected based on a mix of personal and organizational expertise and stakeholder location, to ensure a diversity of views were represented. A total of seven people responded to the email invitation (35\% response rate) and completed the survey. The survey instrument consisted of six open-ended questions, designed to elicit responses on participants' priority pests, perceived risks and benefits of using genetic biocontrol for pest control, and key criteria that might be used to determine support or investment in research and development. The survey also asked participants to reflect on their personal views toward the use of genetic biocontrol for pest control. A final question invited participants to reflect on their personal expectations for the workshop and what they hoped to discuss during sessions.

The data collected from the pre-workshop survey was used to tailor W1 such that it reflected an articulation of the sampled workshop attendees, while acknowledging that those preferences expressed by the subsample may not reflect the broader needs of all workshop participants.

\section{Scene-Setting Presentations}

A series of short informative scene-setting presentations were offered to attendees to orient attention to key topics for discussion in $\mathrm{W} 1$. The presentations were delivered by members of the project team as experts in various aspects of gene drive research and implementation. Topics covered high-level considerations in pest ecology, genetic control of vertebrate invasive species, regulation challenges, and social attitudes toward genetic technologies.

In W2, the online environment and a smaller group setting allowed for more informal orientation to workshop themes. For online sessions, one project team member updated the group on recent research advances and communicated the outcomes of W1.

\section{Construction of Pre-defined Scenarios}

A total of seven (7) pest species scenarios were developed prior to $\mathrm{W} 1$, informed by the pre-workshop survey. These scenarios served to focus discussion on individual species' contexts, harnessing specific expertise and participants' individual interests. Short descriptive narratives outlining the "invasive species problem" in relation to key biological, ecological and economic cost considerations to environment and industry were created. The species for which scenarios were developed included: carp (Cyprinus carpio), feral pigs (Sus scrofa), cane toads (Rhinella marina), foxes (Vulpes vulpes), rodents (Rattus rattus, Mus musculus), feral cats (Felis catus), rabbits (Oryctolagus cuniculus) and invasive pest birds. Box 1 below illustrates the pre-defined scenario developed for rodents.

\section{Group Exercises}

\section{Risk Identification Against Social, Technical and Commercial Criteria}

Participants were divided into six small groups to identify the social, technical, and business/commercial risks, hurdles, and pain points under the assumption that gene drive technology was already available for deployment. Exploration of the risks and benefits of genetic biocontrol was undertaken using group rotations to elicit participants' responses to key questions. In the first rotation, groups were asked to identify a range of painpoints, hurdles and risks relating to either the social, technical or commercial aspects of genetic biocontrol options. A second rotation built on the work of previous groups. A third rotation identified factors to mitigate the key risks identified. Each of the six groups were asked to present mitigation strategies to overcome the hurdles identified to the broader group. Table 2 in Results shows the range of factors identified across social, commercial and technical categories.

\section{Completion of Pre-defined Scenarios}

Participants were invited to self-select into one of seven pest species discussion groups. For each scenario, a narrative describing the invasive species context was presented before a series of questions were asked of group participants to consider. 
BOX 1 | One of seven pre-defined species-specific scenarios developed to gather insights from participating experts.

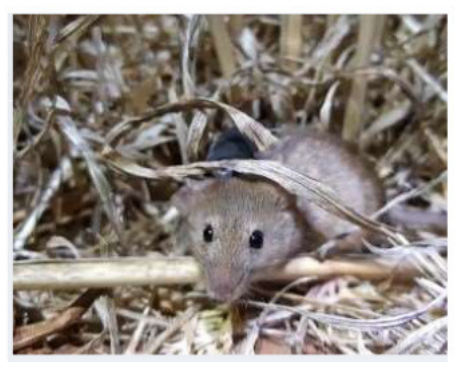

- Small omnivorous mammals with high rates of population increase and turnover.

- Can start breeding at three months of age.

- Gestation period of 21 days and litter sizes of up to 12 pups.

- Can mate the same day as giving birth -> can lead to multiple litters in a good season??

- Average field lifespan $<1$ year.

Plagues of house mice (>1,000 mice/ha) cause enormous economic and social stress to rural communities in Australia. The mouse plague in 1993/94 caused about US\$60 million in damage to crops, intensive livestock industries, and rural communities. In 1999, over 500,000 ha of cropping land was baited with zinc phosphide for mouse control.

The house mouse and the black rat are identified as key threatening processes under New South Wales and Australian environmental legislation, for their role in the extinction of at least 20 species of birds, invertebrates and plants on Lord Howe Island. Introductions of rats on islands have caused ecosystems to breakdown, especially on islands where species have evolved in the absence of mammalian predators. Rats disrupt ecosystem function through predation of animals and plants, which in turn can cause interruption of pollination, nutrient pathways, and seed predation, in some cases leading to forest collapse.

Genetic biocontrol approaches aimed at biasing the sex ratio of rodent populations have been suggested as part of possible eradication of feral rodents from islands. House mice, being the model laboratory animal, are currently being used to test genetic editing techniques though it has not yet been successful in the mammalian model.

For each species, participants were asked to discuss the following questions and document group responses. What do you think are the key challenges when considering a potential genetic biocontrol approach for [rodent] in Australia? How might we overcome these key challenges? How might we deploy genetic technologies to assist [rodent] management? How might we fund the research and development required to advance genetic technologies for [rodent] management? If genetic biocontrol or other ground-breaking strategies were not implemented to control [rodents], what would happen if we continued to rely on current control methods? What are the biggest questions or gaps that need addressing to advance a genetic control approach for this pest?

\section{Pest Prioritization}

A final activity in W1 was a pest prioritization exercise which asked participants to prioritize two individual species for the application of GBT according to multiple criteria including: ecological imperatives; strength of business case; technological development and; social acceptance. The plenary exercise provided both workshop attendees and the project team with insights into the perceived challenges for stakeholders in communicating and investing in GBTs against priority species. The activity used an online voting facility (Zeetings Pty Ltd.) for participants to register their anonymous responses which were relayed to the group in real-time. Figure 2 in Results shows the results of this exercise.

\section{Decision-Making Factors for Investing in Genetic Biocontrol Options}

The primary rationale for understanding the institutional decision-making environment was to identify the full set of factors that influence conditions for investment in GBTs. We refer to conditions as the circumstances, impediments and enablers that facilitate decision-making in this context. Participants were divided into small groups to identify (1) the "push factors" (those factors that are likely to push stakeholders toward investment in GBTs); (2) the "pull factors" (those factors that are likely to "pull" stakeholders away from investment in GBTs and finally; "dealbreakers" (those factors that would be considered unacceptable and likely to derail investment efforts). Table 3 in the Results section identifies the range of influential factors identified by participants for investment in GBTs.

\section{RESULTS}

\section{Pest Priorities and their Technical, Business, Ecological and Social Risks}

Participant responses to the pre-workshop survey revealed the top three priority pests requiring management in Australia to be rabbits, cats and foxes, respectively. When asked to further consider which priority pests in Australia might be most efficacious for genetic biocontrol, participants mostly mentioned rodents and rabbits. The commonly cited reasons for why these particular pests might be most receptive to a genetic control 
option included: species impact, fecundity, existing knowledge about species' biology, and laboratory/controlled trialability.

Table 2 below outlines the range of technical, social and commercial hurdles revealed by $\mathrm{W} 1$ participants to overcome prior to the release of GBTs. Six small groups participated in this exercise across two rotations in W1. Each group's report back was audio-recorded and a thematic summary conducted. Two prominent themes were identified from this exercise. The first, was that resourcing is needed to monitor and evaluate field experience upon release of any genetic control options. The second theme to emerge was the need for coordinated governance to ensure responsible science was conducted and any releases managed appropriately. Unsurprisingly, these themes captured the broad spectrum of political, social and technical categories. In addition, there was some cross-over among the challenges identified where mitigation strategies identified were at times a combination of social, technical or regulatory solutions.

In relation to the application of GBTs against priority species, data were summed in Excel for each of the four criteria tested (i.e., ecological, social, technological and business), for each species. Figure 2 shows the sum of all selections for each species. The five top ranked species for consideration were rodents, rabbits, carp, cane toads and cats. The number of selections for each issue were: ecological imperative $n=64$, social acceptance $n=64$, technological development $n=59$, and strength of business case $n=61$.

Rodents received the most selections (sum $=73$ ) with most selections for technological development $(n=26)$ and business case $(n=22)$. Second ranked were rabbits $(n=55)$ with most selections for business case $(n=24)$ and ecological imperative ( $n$ $=18)$. Third was carp $(n=51)$ with most selections for social

TABLE 2 | Identified commercial, social and technical hurdles to overcome before genetic control options could be implemented.

\section{Rotation 1}

Technical and scientific hurdles, risks and pain points

Social and political hurdles, risks and pain points

Business and commercial hurdles, risks and pain points constructs. the field.
Increased resources. For example, the housing and production of large numbers of animals with genetic

Measuring efficiency and efficacy of gene drives in

Skepticism about the technology being effective. Lack of consensus on the use of GM vertebrates globally

Maintaining commitment and resources from all governments around Australia, probably internationally also for gene drive.

An in-depth review of similar programs is needed to understand the economic, technical and social barriers to previous programs.
Rotation 2

Demonstrating gene drive works in mice, that it's contained, efficacious, specific and can be switched off.

Program derailment through political and social opposition

Opposition resulting from misinformation

Cost recovery; legal risks to scientists in case of off-target effects; managing costs and responsibilities of monitoring.

Potential for current industries to lobby against this technology; market access issues in the global context.

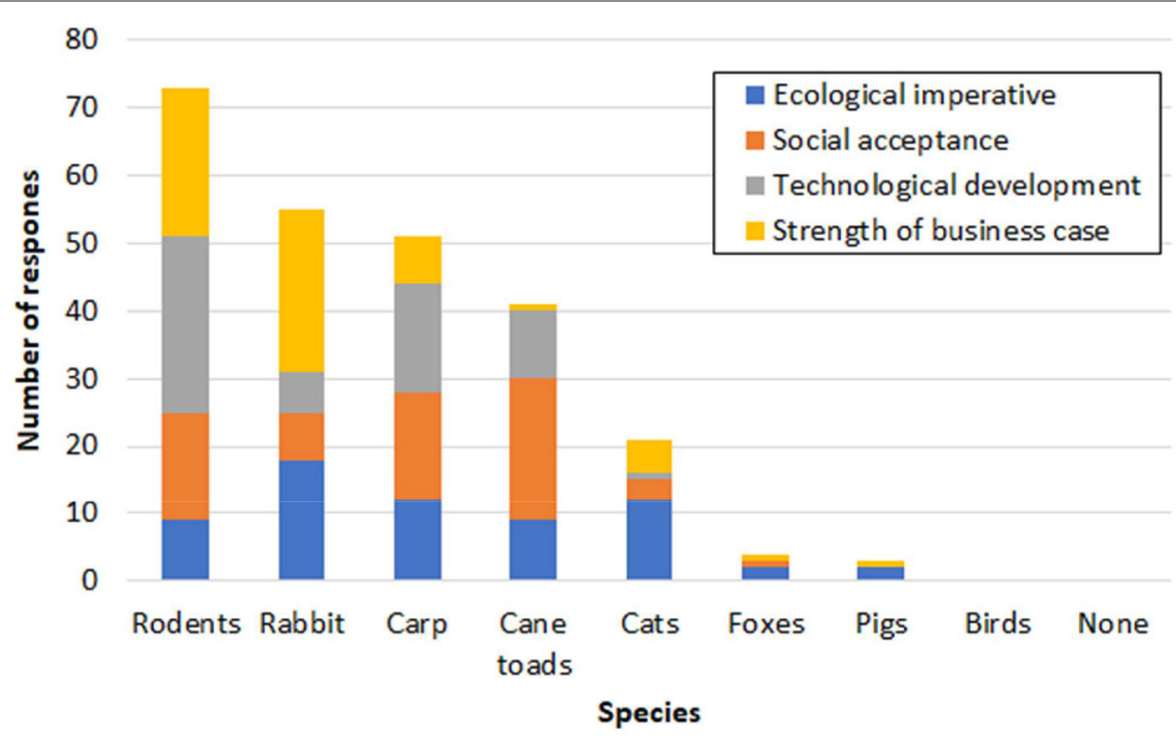

FIGURE 2 | Prioritization of pest species for focus of gene drive research across four dimensions of issues (ecological imperative, social acceptance, technological development and business case). Workshop participants selected two species for each issue. Each bar represents the sum of selections by workshop participants for each issue. 
acceptance $(n=16)$ and technological development $(n=16)$. Fourth was cane toads $(n=41)$ with most selections for social acceptance $(n=21)$ and technological development $(n=10)$. The fifth ranked species was cats $(n=21)$ with most selections for ecological imperative $(n=12)$. The remaining species of foxes $(n=4)$, pigs $(n=3)$, birds $(n=0)$ and none $(n=0)$ had very few selections.

\section{The Institutional Decision-Making Environment}

Decision-makers invited to the online forums for W2 were considered as knowledge holders of organizational decisionmaking processes and held leadership positions in their respective organizations. Group discussions were designed to uncover the processes and drivers that influence how, when and why decisions are made in relation to investment in GBT. Table 3 below captures the multiple pull and push factors identified by Australian decision-makers as influential to decision-making about GBTs.

Online discussions revealed that decisions about pest management are made in complex and dynamic environments (de Graeff et al., 2021a). In addition, decision-making processes and their outcomes have multiple drivers and can be unpredictable. While there exists appetite for considering investing in GBTs among multiple sectors (government, industry and NGOs), the conditions for investment remain significant and as yet unmet. Established safety and efficacy, broad public acceptability and clear drivers for development (as highlighted in the Investment Framework in Figure 1) are among the key conditions identified as essential to investment in GBTs.

When considering conditions for investment in new genetic biocontrol technologies, established safety and efficacy was a recurring theme among participant responses. In addition to

TABLE 3 | The range of factors that influence investment decision-making for key government, industry and civil society stakeholders.

Investment decision-making environment

Push factors (toward investment in genetic biocontrol)

Pull factors (away from investment in genetic biocontrol)

"Dealbreakers" (factors that would be considered unacceptable and likely to derail investment efforts) conforming to existing safety regulations, workshop participants raised concerns about potential unintended consequences of genetic biocontrol technology deployment. These included potential impacts on non-target species (especially charismatic ones), or broadscale "escape" of genetic biocontrol technologies, organisms, or elements beyond targeted populations. Such events were considered to carry an added risk due to potential negative effects on public confidence in genetic biocontrol technologies which has the potential to threaten future viability of such initiatives. Thus, safeguards (e.g., genetic, physical, ecological) to ensure target specificity was a key condition for investment.

\section{DISCUSSION AND IMPLICATIONS FOR GENETIC BIOCONTROL IN AUSTRALIA AND ELSEWHERE}

There is much global interest in developing novel methods for managing invasive pests, but most countries and governments are unsure how to go about initiating research and development in a responsible and inclusive way (Brown et al., 2018). The Decision Investment Framework developed here (Figure 1) has identified key considerations for Australian stakeholders for investment in GBTs. The conditions identified by our Australianbased workshops are not dissimilar to those identified elsewhere (cf. Brown et al., 2018; Moro et al., 2018; de Graeff et al., 2021a). These findings can inform other research consortiums on the types of enablers and constraints for investing in GBTs to manage current and future vertebrate pest incursions. The framework also highlights remaining knowledge gaps for science, including directions for continued social science investigation. The inclusion of Traditional knowledge contribution also requires further consideration.

In relation to developing a better understanding of public engagement with science, there are multiple and interrelated areas of scientific and professional enquiry possible. These span social scientific enquiry (i.e., public attitudes and perceptions of risk, drivers for technology acceptance and uptake, bioethics, institutional arrangements) to understand the broader context of the technology implementation environment; public engagement (e.g., consulting with and working with the public to listen and acknowledge concerns and provide feedback); and science communication (e.g., providing information about new technologies to keep the public informed). While these can overlap, their intentions and goals require careful unpacking (Moon and Blackman, 2015; Smith et al., 2021).

Given the many uncertainties relating to readiness and acceptability of genetic biocontrol to date, public "acceptance" itself may not be a prerequisite for researchers nor investors wishing to pursue genetic biocontrol. Instead, pursuing outcomes that more broadly reflect public tolerability toward innovative solutions, or seeking to genuinely engage affected groups in dialogue are more likely to build trusted relationships with segments of society. Clarity about engagement purpose and strategy is critical to a transparent process. Employing the appropriate process for the expected outcome is the most effective approach to incorporating stakeholder 
perspectives in complex scientific endeavors such as genetic biocontrol technologies.

Genetic biocontrol technology solutions are complex to understand and communicate and require substantive and constructive discourse with communities likely affected. As such, this paper strongly supports investment in both social science investigation alongside biotechnology development, in addition to well-considered engagement processes which include diverse sections of society. Involvement of Traditional Owners, and broader Aboriginal and Torres Strait Islander communities to co-develop culturally acceptable plans for deployment is an example of the depth of engagement required in responsible science development.

Reflecting on the original research questions, the current priorities for Australian stakeholders in managing the impact of pest species are influenced by a range of interrelated and at times competing drivers. Jurisdictional boundaries, diverse and multi-layered governance structures and a commitment to balancing the risks and benefits of management options are at the forefront of decision-making for the stakeholders we engaged. Rabbits, cats and foxes were identified as key priority species for pest management in Australia, while rodents and rabbits were considered ideal species candidates for genetic biocontrol. The primary factors which are likely to influence Australian stakeholder investment in GBTs include: established safety and efficacy; social acceptability and robust drivers for development and deployment of the technology.

While our exercise demonstrated a replicable methodological approach for gathering diverse perspectives and identifying priorities in different settings, the research conducted carried one major limitation. The Investment Framework is skewed by Western models of science which have historically largely neglected Indigenous perspectives and knowledge, including alternative assessments of risk (Taitingfong, 2020). As mentioned earlier, our workshops did not explicitly engage Indigenous and Traditional Owner perspectives in development of the Framework. Future research should prioritize engagement with Indigenous land managers and Traditional Owner groups to gain a fuller understanding of the potential impact of GBTs on heritage and cultural values held by Indigenous Australians and more broadly on country and kinship. The funding and planning

\section{REFERENCES}

Abstracts from the UC Davis Transgenic Animal Research Conference X (TARC X, 2016). Tahoe City, CA, USA, August 9-12, 2015. Transg. Res. 25, 101-122. doi: $10.1007 /$ s1 1248-015-9915-3

Bradshaw, C. J. A., Hoskins, A. J., Haubrock, P. J., Cuthbert, R. N., Diagne, C., Leroy, B., et al. (2021). Detailed assessment of the reported economic costs of invasive species in Australia. Neobiota 67, 511-550. doi: $10.3897 /$ neobiota.67.58834

Braysher, M. (2017). Managing Australia's Pest Animals: A Guide to Strategic Planning and Effective Management. Clayton South, VIC: CSIRO Publishing, 200. doi: $10.1071 / 9781486304448$

Brossard, D., Belluck, P., Gould, F., and Wirz, C. D. (2019). Promises and perils of gene drives: navigating the communication of complex, post-normal science. Proc. Natl. Acad. Sci. U. S. A. 116, 7692-7697. doi: 10.1073/pnas.18058 74115 of science often prioritizes expert knowledge of limited type, especially in regard to social risk (Moon and Blackman, 2015). Inclusion of alternate knowledge categories so that conclusions about how risk at community level, for example, reflect reality, is essential to informed decision-making in relation to GBTs.

\section{DATA AVAILABILITY STATEMENT}

The datasets presented in this article are not readily available due to human research ethics protection, the raw data used in this analysis is currently re-identifiable. Requests to access the datasets should be directed to the corresponding author.

\section{ETHICS STATEMENT}

This study involved human participants and was granted ethics approval by the CSIRO Social and Interdisciplinary Human Research Committee. The participants involved provided their informed consent to participate in this study.

\section{AUTHOR CONTRIBUTIONS}

LC led the design and drafting of the output. LC, AM, SC, $\mathrm{WR}, \mathrm{KO}, \mathrm{MB}, \mathrm{PB}, \mathrm{MT}$, and TS contributed to the acquisition of research data including planning and design of workshops. $\mathrm{LC}, \mathrm{AM}, \mathrm{WR}, \mathrm{KO}$, and $\mathrm{PB}$ were involved in the analysis and interpretation of data. Each author assisted in critically revising sections of the manuscript. The project was initially conceived by MT with leadership in project coordination by WR and domain leader TS. All authors made contributions of specialist knowledge to the manuscript.

\section{ACKNOWLEDGMENTS}

The authors wish to thank attendees of both workshops for their contributions to the development of the Framework. We also wish to thank Raghu Sathyamurthy and Tim Doran for their helpful comments in previous versions of the paper. Finally, we are grateful to David Romano from PiqueGlobal for his expert facilitation of both workshops.

Brown, Z. S., Carter, L., and Gould, F. (2018). An introduction to the proceedings of the environmental release of engineered pests: building an international governance framework. BMC Proc. 12:10. doi: 10.1186/s12919-018-0105-1

Campbell, K. J., Beek, J., Eason, C. T., Glen, A. S., Godwin, J., Gould, F., et al. (2015). The next generation of rodent eradications: innovative technologies and tools to improve species specificity and increase their feasibility on islands. Biol. Conserv. 185, 47-58. doi: 10.1016/j.biocon.2014.10.016

Carter, L., Mankad, A., Hobman, E. V., and Porter, N. B. (2021). Playing God and tampering with nature: popular labels for real concerns in synthetic biology. Transg. Res. 30, 155-167. doi: 10.1007/s11248-021-00233-2

Carter, L., Mankad, A., Zhang, A., Curnock, M. I., and Pollard, C. R. J. (2020). A multidimensional framework to inform stakeholder engagement in the science and management of invasive and pest animal species. Biol. Invas. 23, 625-640. doi: 10.1007/s10530-020-02391-6

Clark, L., Eisemann, J., Godwin, J., Horak, K. E., Oh, K. P., O’Hare, J., et al. (2020). "Invasive species control and resolution of wildlife damage conflicts: 
a framework for chemical and genetically based management methods," in GMOs. Topics in Biodiversity and Conservation, Vol. 19, eds A. Chaurasia, D. L. Hawksworth, and M. Pessoa de Miranda (Cham: Springer). p. 193-222. doi: 10.1007/978-3-030-53183-6_9

Courchamp, F., Chapuis, J.- L., and Pascal, M. (2003). Mammal invaders on islands: impact, control and control impact. Biol. Rev. 78, 347-383. doi: $10.1017 /$ S1464793102006061

David, A. S., Kaser, J. M., Morey, A. C., Roth, A. M., and Andow, D. A. (2013). Release of genetically engineered insects: a framework to identify potential ecological effects. Ecol. Evol. 3, 4000-4015. doi: 10.1002/ece3.737

de Graeff, N., Jongsma, K. R, Lunshof, J. E., and Bredenoord, A. L. (2021a). Governing gene drive technologies: a qualitative interview study. AJOB Empir. Bioeth. doi: 10.1080/23294515.2021.1941417. [Epub ahead of print].

de Graeff, N., Jongsma, K. R., and Bredenoord, A. L. (2021b). Experts' moral views on gene drive technologies: a qualitative interview study. BMC Med. Ethics 22:25. doi: 10.1186/s12910-021-00588-5

Doherty, T. S., Dickman, C. R., Johnson, C. N., Legge, S. M., Ritchie, E. G., and Woinarski, J. C. Z. (2016). Impacts and management of feral cats Felis catus in Australia. Mamm. Rev. 47, 83-97. doi: 10.1111/mam.12080

Emerson, C., James, S., Littler, K., and Randazzo, F. (2017). Principles for gene driver research. Science 358, 1135-1136. doi: 10.1126/science.aap9026

Epanchill-Niell, R. S. (2017). Economics of invasive species policy and management. Biol. Invas. 19, 3333-3354. doi: 10.1007/s10530-017-1406-4

Hampton, J. O., Fisher, P. M., and Warburton B. (2020). Reconsidering humanness. Conserv. Biol. 34, 1107-1113. doi: 10.1111/cobi.13489

Hart and Bomford (2006). Australia's Pest Animals: New Approaches to Old Problems. Canberra, ACT: Bureau of Rural Sciences.

Hartley, S., Gillund, F., and van Hove, L., Wickson,. F. (2016). Esential fearures of responsible governance of agricultural biotechnology. PLoS Biol. 14:e1002453. doi: 10.1371/journal.pbio.1002453

Hayes, K. R., Hosack, G. R., Dana, G. V., Foster, S. D., Ford, J. H., Thresher, R., et al. (2018). Identifying and detecting potentially adverse ecological outcomes associated with the release of gene-drive modified organisms. J. Respons. Innov. 5, S139-S158. doi: 10.1080/23299460.2017.1415585

Kearney, S. G., Cawardine, J., Reside, A., Fisher, D. O., Maron, M., Doherty, T. S., et al. (2019). The threats to Australia's imperilled species and implications for a national conservation response. Pac. Conserv. Biol. 25:328. doi: 10.1071/PC18024_CO

Kirk, N., Kannemeyer, R., and Greenaway, A., MacDonald, E., and Stronge, D. (2020). Understanding attitudes on new technologies to manage invasive species. Pac. Conserv. Biol. 206, 35-44. doi: 10.1071/PC18080

Knipple, D. C. (2013). Prospects for the use of transgenic approaches to improve the efficacy of the sterile insect technique (SIT) for control of the codling moth Cydia pomonella Lennaeus (Lepidoptera: Tortricidae). Crop Protect. 44, 142-146. doi: 10.1016/j.cropro.2012.11.010

Kofler, B. N., Collins, J. P., Kuzma, J., Marris, E., Esvelt, K., Nelson, M. P., et al. (2018). Edit. Nat. Local Roots Glob. Govern. 362, 527-530. doi: $10.1126 /$ science.aat 4612

Kopf, R. K., Nimmo, D. G., Humphries, P., Baumgartner, L. J., Bode, M., Bond, N. R, et al. (2017). Confronting the risks of large-scale invasive species control. Nat. Ecol. Evol. 1:172. doi: 10.1038/s41559-017-0172

Kuzma, J., Gould, F., Brown, Z., Collins, J., Delborne, J., Frow, E., et al. (2018). A roadmap for gene drives: using institutional analysis and development to frame research needs and governance in a systems context. J. Respons. Innov. 5, 13-39. doi: 10.1080/23299460.2017.1410344

Kuzma, J., and Rawls, L. (2016). Engineering the wild: Gene drives and intergenerational equity. Jurimetrics $56,280-286$.

Ledingham, K., and Hartley, S. (2021). Transformation and slippage in coproduction ambitions for global technology development: the case of gene drive. Environ. Sci. Policy 116, 778-785. doi: 10.1016/j.envsci.2020.10.014

Legros, M., Marshall, J. M., Macfadyen, S., Hayes, K. R., and Sheppard, A. (2021). Gene drive strategies of pest control in agricultural systems: challenges and opportunities. Evol. Applic. 14, 2162-2178. doi: 10.1111/eva.13285

Leitschuh, C. M., Kanavy, D., Backus, G. A., Valdez, R. X., Serr, M., Pitts, E. A., et al. (2018). Developing gene drive technologies to eradicate invasive rodents from islands. J. Respons. Innov. 5, S121-S138. doi: 10.1080/23299460.2017.13 65232
Littin, K., Fisher, P., Beausoleil, J. J., and Sharp, T. (2014). Welfare aspects of vertebrate pest control and culling: ranking control techniques for humaneness. Rev. Sci. Tech. Off. Int. Epiz. 33, 281-289. doi: 10.20506/rst.33.1.2281

MacDonald, E. A., Balanovic, J., Edwards, E. D., Abrahamse, W., Frame, B., Greenaway, A., et al. (2020). Public opinion towards gene drive as a pest control approach for biodiversity conservation and the association of underlying worldviews. Environ. Commun. 14, 904-918. doi: 10.1080/17524032.2019.1702568

Macnaughten, P., and Chilvers, J. (2014). The future of science governance: publics, policies and practices. Environ. Plann. C Govern. Policy 32, 530-548. doi: $10.1068 / \mathrm{c} 1245 \mathrm{j}$

Mankad, A., Hobman, E. V., and Carter, L. (2020). Effects of knowledge and emotion on support for novel synthetic biology applications. Conserv. Biol. 35, 623-633. doi: 10.1111/cobi.13637

Mankad, A., Kennedy, U., and Carter L. (2019). Biological control of pests and a social model of animal welfare. J. Environ. Manag. 247, 313-322. doi: 10.1016/j.jenvman.2019.06.080

McFarlane, G. R., Whitelaw, C. B. A., and Lillico, S. G. (2018). CRISPRbased gene drives for pest control. Trends Biotechnol. 36, 130-133. doi: 10.1016/j.tibtech.2017.10.001

McLeod, R. (2016). Cost of Pest Animals in NSW and Australia, 2013-14. eSYS Development Pty Ltd, 2016. Report prepared for the NSW Natural Resources Commission. Available online at: https://invasives.com.au/wp-content/ uploads/2019/02/Cost-of-Pest-Animals-in-NSW-and-Aus-2013-14-webHR.pdf

Molsher, R., Newsome, A. E., Newsome, T. M., and Dickman, C. R. (2017). Mesopredator management: effects of red fox control on the abundance, diet and use of space by feral cats. PLOS ONE 12:e0168460. doi: 10.1371/journal.pone.0168460

Moon, K., and Blackman,. D. (2015). A guide to understanding social science research for natural scientists. Conserv. Biol. 28, 1167-1177. doi: 10.1111/cobi.12326

Moro, D., Byrne, M., Kennedy, M., Campbell, S., and Tizard, M. (2018). Identifying knowledge gaps for gene drive research to control invasive animal species: the next CRISPR step. Glob. Ecol. Conserv. 13:e00363. doi: 10.1016/j.gecco.2017.e00363

National Academy of Sciences Engineering and Medicine (NASEM) (2016). Gene Drives on the Horizon: Advancing Science, Navigating Uncertainty, and Aligning Research with Public Values. Washington, DC: National Academies Press.

Oye, K. A., Esvelt, K., Appleton, E., Catteruccia, F., Church, G., Kuiken, T., et al. (2014). Regulating gene drives. Science 345, 626-628. doi: $10.1126 /$ science. 1254287

Pimentel, P. D. D. (2002). Biological Invasions: Economic and Environmental Costs of Alien Plant, Animal, and Microbe Species, 1st Edn. New York, NY: CRC Press. doi: 10.1201/9781420041668

Prowse, T. A., Cassey, P., Ross, J. V., Pfitzner, C., Wittmann, T. A., and Thomas, P. (2017). Dodging silver bullets: good CRISPR gene-drive design is critical for eradicating exotic vertebrates. Proc. R. Soc. B Biol. Sci. 284:20170799. doi: 10.1098/rspb.2017.0799

Reed, M. S., and Curzon, R. (2015). Stakeholder mapping for the governance of biosecurity: a literature review. J. Integr. Environ. Sci. 12, 15-38. doi: 10.1080/1943815X.2014.975723

Royal Society Te Apãrangi (2019). Gene Editing; Legal and Regulatory Implications. Report for the Royal Soceity of Te Apãrangi, August 2019.Available online at: https://www.royalsociety.org.nz/what-we-do/our-expert-advice/all-expertadvice-papers/gene-editing-legal-and-regulatory-implications/ (accessed December 29, 2021).

Rudenko, L., Palmer, M. J., and Oye, K. (2018). Considerations for the governance of gene drive organisms. Pathog. Glob. Health 112, 162-181. doi: 10.1080/20477724.2018.1478776

Santos, M. R. (2020). "Evaluating gene drive approches for public good," in GMOs. Topics in Biodiversity and Conservation, Vol. 19, eds A. Chaurasia, D. L. Hawksworth, and M. Pessoa de Miranda (Cham: Springer). p. 421-437.

Shackleton, R. T., Adriaens, T., Brundu, G., Dehnen-Schmutz, K., Estévez, R. A., Fried, J., et al. (2019). Stakeholder engagement in the study and management of invasive alien species. J. Environ. Manag. 229, 88-101. doi: 10.1016/j.jenvman.2018.04.044 
Smith, R. D. J., Hartley, S., Middleton, P., and Jewitt, T. (2021). Knowing when to talk? Plant genome eidting as a sit for pre-engagment institutional reflexivity. Public Underst. Sci. 30, 740-758. doi: 10.1177/0963662521999796

Synthetic Biology Future Science Platform (2020). Public Perceptions of Using Synthetic Biology to Manage Invasive Pests. CSIRO, Australia. Available online at: https://research.csiro.au/synthetic-biology-fsp/wp-content/uploads/sites/ 140/2021/06/20-00137_LW_SynBioSurveyResults_InvasiveSpecies_WEB_ 210527.pdf.

Taitingfong, R. I. (2020). Islands as laboratories: indigenous knowledge and gene drives in the Pacific. Hum. Biol. 91, 179-188. doi: 10.13110/humanbiology.91.3.01

Teem, J. L., Alphey, L., Descamps, S., Edgington, M. P., Edwards, O., Gemmell, N., et al. (2020). Genetic biocontrol for invasive species. Front. Bioeng. Biotechnol. 8:452. doi: $10.3389 /$ fbioe. 2020.00452

Thizy, D., Emerson, C.l., Gibbs, J., Hartley, S., Kapiriri, L., Lavery, J., et al. (2019). Guidance on stakeholder engagement practices to inform the development of area-wide vector control methods. PLoS Negl. Trop. Dis. 13:e0007286. doi: 10.1371/journal.pntd.0007286

Thresher, R. E., and Kuris, A. M. (2004). Options for managing invasive marine species. Biol. Invas. 6, 295-300. doi: 10.1023/B:BINV.0000034598.28718.2e

Unckless, R. L., Clark, A. G., and Messer, P. W. (2017). Evolution of resistance against CRISPR/Cas9 gene drive. Genetics 205, 827-841. doi: 10.1534/genetics.116.197285

Urquhart, J., Potter, C., Barnett, J., Fellenor, J., Mumford, J., and Quine, C. P. (2017). Expert risk perceptions and the social amplication of risk: a case study in invasive tree pests and diseases. Environ. Sci. Policy 77, 172-178. doi: 10.1016/j.envsci.2017.08.020

Webber, B. L., Raghu, S., and Edwards, O. R. (2015). Opinion: Is CRISPRbased gene drive a biocontrol silver bullet or global conservation threat? Proc. Natl. Acad. Sci. U. S. A. 112, 10565-10567. doi: 10.1073/pnas.15142 58112

Conflict of Interest: The authors declare that the research was conducted in the absence of any commercial or financial relationships that could be construed as a potential conflict of interest.

Publisher's Note: All claims expressed in this article are solely those of the authors and do not necessarily represent those of their affiliated organizations, or those of the publisher, the editors and the reviewers. Any product that may be evaluated in this article, or claim that may be made by its manufacturer, is not guaranteed or endorsed by the publisher.

Copyright (C) 2022 Carter, Mankad, Campbell, Ruscoe, Oh, Brown, Byrne, Tizard and Strive. This is an open-access article distributed under the terms of the Creative Commons Attribution License (CC BY). The use, distribution or reproduction in other forums is permitted, provided the original author(s) and the copyright owner(s) are credited and that the original publication in this journal is cited, in accordance with accepted academic practice. No use, distribution or reproduction is permitted which does not comply with these terms. 